\title{
Self-care Practices of Type 2 Diabetes Patients by Socio-demographic and Clinical Factors: An Ordered Probit Model
}

\author{
Imran Hameed Khaliq ${ }^{1}$, Hafiz Zahid Mahmood², Nusrat Manzoor ${ }^{3}$, Farhan \\ Hameed Khaliq ${ }^{4}$, Khadija Asim¹, Yaseen Abdullah', Itzaz Aslam ${ }^{5}$, and Shakila \\ Zaman' \\ ${ }^{1}$ Department of Public Health, University of Health Sciences, Lahore, Pakistan \\ ${ }^{2}$ Department of Economics, COMSATS University Islamabad, Lahore Campus, Pakistan \\ ${ }^{3}$ Department of Obstetrics and Gynaecology, Rai Medical College, Sargodha, Pakistan \\ ${ }^{4}$ Hussain College of Health Sciences, Lahore, Pakistan \\ ${ }^{5}$ Johar Institute of Professional Studies, Lahore, Pakistan
}

Corresponding Author: Imran Hameed Khaliq; Department of Public Health, University of Health Sciences, Khayaban-e-Jamia Punjab, Lahore-54600, Pakistan Tel: +923227171089 email: imranham90@gmail.com imranhameed@uhs.edu.pk

Received 23 August 2019 Accepted 14 December 2019 Published 30 December 2019

Production and Hosting by Knowledge E

(c) Imran Hameed Khaliq et al. This article is distributed under the terms of the

Creative Commons

Attribution License, which permits unrestricted use and redistribution provided that the original author and source are credited.

Editor-in-Chief:

Prof. Mohammad A. M. Ibnouf

\section{Abstract}

Background: Diabetes prevalence has risen more rapidly in middle- and low-income countries and has emerged as the seventh highest cause of death in such countries. Socio-demographics, patient knowledge and clinical factors, such as family history of diabetes, have a vital effect on the disease outcomes. This study assessed self-care practices among patients with type 2 diabetes to determine the probability of self-care by predictor variables, including socio-economic and clinical factors, and quantify the marginal effects of these independent variables on different self-care practices among diabetic patients.

Methods: This exploratory study collected data from 200 type 2 diabetes patients at a branch of private pharmacy in Pakistan using a convenient sampling technique and a semi-structured questionnaire. An ordered probit regression model was used to analyze the different self-care practices among diabetic patients. With self-practices ordered in four classes from poor to good, the marginal effects of each socio-economic and clinical factors were also calculated on the likelihood of aforesaid self-care practices among diabetic patients.

Results: Results showed that the relationships of household income, patient's choice of private or public hospital for treatment, and patient's weight with selfcare probability were statistically significant. These socio-demographics and clinical indicators significantly influenced each category of self-care practices.

Conclusion: Socio-demographic and clinical factors played a decisive role in the healthcare practices among type- 2 diabetes patients. Monthly household income, patient's choice of private or public hospital for treatment, and patient's weight influenced different levels of self-care practices. Income had a negative contribution in poor and fair self-care levels of practices, whereas it had a positive role in average and good self-care levels of practices.

Keywords: type 2 diabetes; self-care practices; socio-economic factors; developing country 


\section{Introduction}

Worldwide, diabetes is a chronic disease affecting 450 million people [1]. The global prevalence of diabetes among adults over 18 years of age was $8.5 \%$ in 2014 [2]. In 2015 , complications related to diabetes resulted in 1.5 million deaths worldwide, and high blood glucose was the cause of another 2.2 million deaths in 2012 [3]. Diabetes prevalence has been rising more rapidly in middle- and low-income countries and has emerged as the seventh highest cause of death in such countries [4]. The prevalence rate of diabetes in Pakistan is $9.8 \%$, with the disease affecting males (10.0\%) and females (9.7\%) nearly equally [5]. In 2017, there were $7,474,000$ cases of diabetes in Pakistan [1].

Pakistan has a high prevalence of diabetes and is expected to experience further rises in the disease with advancing urbanization and associated factors of unhealthy lifestyles, genetic predisposition, maternal and fetal malnutrition, reduced physical activity, obesity, increased caloric intake and increased smoking rates [6-8]. In addition, management of diabetes and its risk factors remains suboptimal in Pakistan $[9,10]$. In 2016, complications related to diabetes were responsible for 7,210 male and 9,180 female deaths among persons aged 30-69 years and 9,560 male and 12,800 female deaths among persons aged 70 years and older [11].

Diabetes is not a curable disease, but it is controllable; however, if the disease is not controlled, it can lead to poor health, multiple systematic complications and premature death [11]. Appropriate self-care practices are critical if individuals with the condition are to minimize their risk of diabetes complications and ensure improved overall health outcomes irrespective of the type of diabetes [12]. These self-care practices relate to age, gender, marital status, education, rural background, family system and socioeconomic status among persons with diabetes [13-16]. Socio-demographics, patient knowledge and culture have a vital effect on the disease outcomes [17]. Moreover, clinical factors also affect the self-care management among diabetes patients, including glycated hemoglobin levels, treatment received according to the type of diabetes, proper compliance to medication, proper follow-up visits to diabetes clinics and presence of risk factors [18].

Both the immediate and life-long impact of diabetes represents a significant burden for healthcare settings. In Pakistan, current health expenditure per capita is US \$37, which is below the WHO recommended standard of US \$44; as a result, a number of ill persons struggle to accomplish healthy outcomes through the internationally recommended lifestyle modifications [19]. Given the rapidly increasing prevalence of diabetes in Pakistan, a focus on treatment is crucial. Unfortunately, only $58 \%$ of Pakistani 
citizens have an education level of 10 years and above [19]. Indeed, diabetes is a chronic disease for which self-care and socio-demographic and clinical factors must be addressed. Therefore, the objectives of this study were to assess the self-care practices among diabetic patients, determine the probability of self-care among the target patients by socio-economic and clinical factors and quantify the marginal effects of these independent variables on different self-care practices among diabetic patients.

\section{Methods}

\subsection{Ethical approval}

The survey was approved by the Ethical Review Committee, Hussain College of Health Sciences/Hussain Memorial Hospital, Lahore (No. HCSC/18/ERC/105). All patients in the study provided written informed consent.

\subsection{Study design and setting}

This exploratory study was conducted between April and June 2018 at the Hussain Memorial Hospital pharmacy and a branch of Clinix Pharmacy, Lahore, Pakistan. Moreover, this study protocol adhered to international ethical guidelines for health-related research involving humans [18].

\subsection{Inclusion/exclusion criteria}

Inclusion criteria consisted of individuals who were 18 years of age or older, diagnosed with type 2 diabetes at least three years prior at the time of interview and able to provide informed consent. Patients who were unable to understand and speak English, Urdu, Saraiki or Punjabi were excluded from the study.

\subsection{Sample size and sampling technique}

All patients who fulfilled the inclusion criteria during the study period were included in the study using a purposive sampling technique. 


\subsection{Study instrument development}

The multi-disciplinary team of authors developed a semi-structured questionnaire based on literature [20, 21]. The questionnaire was validated in two steps. First, the questionnaire was sent to a diabetes and endocrinology consultant of a private hospital situated in Lahore, who provided his expert opinion on the elements of the instrument with respect to importance, simplicity and relativity. Second, the survey instrument was pre-tested with 10 diabetic patients to assess presentation, acceptability and ease of understanding of the questions. According to feedback, the questionnaire was slightly modified prior to use.

\subsection{Data collection}

The instrument was consisted of three parts:

Demographic Characteristics: Eight survey items assessed demographic information of the target patients. Respondents were asked to describe their age in years (below 21, 21-30, 31-40, 41-50, 51 and above), gender (male, female), highest level of education (illiterate, literate with no formal education, high school/10th standard, intermediate/12th standard, graduate, post graduate/doctorate), marital status (married, unmarried), monthly household income in Pakistani Rupees (10,000-20,000, 20,001$30,000,30,001-40,000,40,001-50,000$, above 50,000), patient family system (joint family system, nuclear family system), rural background of the patient (yes, no) and preferable patient care center (government hospitals, private hospitals, private clinics).

Medical Characteristics: Two open-ended questions assessed the medical characteristics of the patients: duration of diabetes mellitus in years and patient weight in kilograms.

Variables to Measure the Self-Care Practices of Diabetic Patients: Three survey items were included in the questionnaire to compute the self-care practices of diabetic patients by adding binary variables of regular exercise (yes $=1$, otherwise 0 ), cereal foods intake (yes $=1$, otherwise 0 ) and regular self-diabetes check at home (yes $=1$, otherwise 0).

\subsection{Statistical analysis}

Descriptive statistics were rendered for the key variables by estimating frequencies, percentages and measures of central tendencies. 
Econometric Model: An ordered probit model was used to analyze the different selfcare practices among diabetic patients. This model accounted for interdependencies among explanatory variables, marginal effects and statistical significance of variables to demonstrate the comparative degrees to which different factors and combinations of factors account for the different levels of self-care practices of diabetic patients.

A set of demographic and medical indicators was chosen as explanatory variables, including age, gender, marital status of the diabetic patients, household income, dummy of rural background of patients (rural area $=1$, otherwise 0 ), patient's family system (joint family $=1$, otherwise 0), duration of diabetes mellitus (in years), patient's weight (in kilograms), duration of diabetes in other family members (in years), dummy of private hospital treatment (yes $=1$, otherwise 0 ), dummy of private clinic treatment (yes $=1$, otherwise 0), dummy of government hospital treatment (yes = 1, otherwise 0 ), which were denoted by $X_{1}, X_{2}, X_{3}, X_{4}, X_{5}, X_{6}, X_{7}, X_{8}, X_{9}, X_{10}$, and $X_{11}$, respectively. Different self-care practices of diabetic patients were taken as the dependent variable $(Y)$ that showed different self-care practices. The levels of self-care were scored as the following: poor self-care practices $=0$, fair self-care practices $=1$, average self-care practices $=2$ and good self-care practices $=3$. Self-care practices were computed by adding dummy variables of regular exercise (yes $=1$, otherwise 0 ) cereal foods intake (yes $=1$, otherwise 0 ) and regular self-diabetes check (yes $=1$, otherwise 0 ) at home.

Stata 10 (StataCorp LLC Texas, USA) was employed to render econometric analysis to achieve the results of the study.

\section{Results}

Table 1 shows that $64.5 \%$ of the diabetic patients were females. Fifty-five per cent of patients were $41-50$ years of age, followed by $31-40$ years (34.5\%), 51 years and above (7.5\%), 21-30 years (2.5\%) and below 21 years (0.5\%). Sixty-five per cent of patients were married, and 74\% patients were living in joint family systems. Fifty-six per cent of patients' families had rural backgrounds, and patients had been suffering from diabetes for 7.46 years on average $(S D=2.75)$ at the time of data collection.

Table 2 shows the ordered probit regression results, which describe the impact of independent variables on the probability of self-care practice levels. There were insignificant relationships of demographic indicators, including age, gender, marital status, rural background of patients and family system, with the probabilistic change in self-care practices among diabetic patients. Income was statistically significant at the highest level (less than 1\%) and positively affected the probability of self-care practices 
TABLE 1: Demographic/clinical characteristics of diabetes patients $[N=200]$.

\begin{tabular}{|c|c|c|c|c|c|}
\hline \multicolumn{2}{|c|}{ Variable } & \multirow{2}{*}{$\begin{array}{c}\text { Frequency } \\
1\end{array}$} & \multirow{2}{*}{$\begin{array}{c}\begin{array}{c}\text { Percent } \\
\text { [\%] }\end{array} \\
0.5\end{array}$} & \multirow{2}{*}{$\begin{array}{c}\text { Mean } \\
-\end{array}$} & \multirow{2}{*}{$\begin{array}{c}\text { Standard } \\
\text { Deviation } \\
-\end{array}$} \\
\hline Age [in years] & Below 21 & & & & \\
\hline & $21-30$ & 5 & 2.5 & - & - \\
\hline & $31-40$ & 69 & 34.5 & - & - \\
\hline & $41-50$ & 110 & 55 & - & - \\
\hline & 51 and above & 15 & 7.5 & - & - \\
\hline \multirow[t]{2}{*}{ Gender } & Male & 71 & 35.5 & - & - \\
\hline & Female & 129 & 64.5 & - & - \\
\hline \multirow[t]{2}{*}{ Marital status } & Unmarried & 71 & 35.5 & - & - \\
\hline & Married & 129 & 64.5 & - & - \\
\hline \multirow{6}{*}{$\begin{array}{l}\text { Educational } \\
\text { qualification [in years] }\end{array}$} & Illiterate & 51 & 25.5 & - & - \\
\hline & $\begin{array}{l}\text { Literate with no formal } \\
\text { education }\end{array}$ & 37 & 18.5 & - & - \\
\hline & High school / 10th standard & 41 & 20.5 & - & - \\
\hline & $\begin{array}{l}\text { Intermediate / 12th } \\
\text { Standard }\end{array}$ & 40 & 20 & - & - \\
\hline & Graduate & 21 & 10.5 & - & - \\
\hline & Post Graduate / Doctorate & 10 & 5 & - & - \\
\hline \multirow{4}{*}{$\begin{array}{l}\text { Household income [in } \\
\text { Rs.] }\end{array}$} & $10,000-20,000$ & 5 & 2.5 & - & - \\
\hline & $20,001-30,000$ & 21 & 10.5 & - & - \\
\hline & $30,001-40,000$ & 53 & 26.5 & - & - \\
\hline & $40,001-50,000$ & 51 & 25.5 & - & - \\
\hline \multirow[t]{2}{*}{ Patient family system } & Nuclear Family System & 52 & 26 & - & - \\
\hline & Joint Family System & 148 & 74 & - & - \\
\hline $\begin{array}{l}\text { Rural background of } \\
\text { patient }\end{array}$ & - & 111 & 55.5 & - & - \\
\hline \multirow{3}{*}{$\begin{array}{l}\text { Preferable patient care } \\
\text { center }\end{array}$} & Government Hospital & 70 & 35 & - & - \\
\hline & Private Hospital & 84 & 42 & - & - \\
\hline & Private Clinic & 46 & 23 & - & - \\
\hline $\begin{array}{l}\text { Duration of diabetes } \\
\text { mellitus [in years] }\end{array}$ & - & - & - & 7.46 & 2.75 \\
\hline $\begin{array}{l}\text { Patient weight [in } \\
\text { kilograms] }\end{array}$ & - & - & - & 71.63 & 14.66 \\
\hline
\end{tabular}


among the diabetic patients. Specifically, a rise in income by one Pakistani Rupee (PKR) increased the probability of self-care practices by $0.23 \%$.

TABLE 2: Probability of self-care practices change due to demographic and medical factors $[N=200]$ using [statistical procedure]

\begin{tabular}{|l|c|c|c|c|c|}
\hline Indicators & Coefficient & $\begin{array}{c}\text { Standard } \\
\text { Error }\end{array}$ & P-value & \multicolumn{2}{c}{ 95\% Confidence Interval } \\
\hline Age & 0.06 & 0.12 & 0.611 & -0.17217 & 0.29307 \\
\hline Gender & 0.31 & 0.33 & 0.344 & -0.33203 & 0.95190 \\
\hline Dummy-marital status & -0.27 & 0.32 & 0.405 & -0.91055 & 0.36740 \\
\hline Household income & 0.23 & 0.07 & 0.001 & 0.10398 & 0.39458 \\
\hline Rural background of patient & 0.18 & 0.16 & 0.265 & -0.13575 & 0.49301 \\
\hline Family system & 0.05 & 0.18 & 0.760 & -0.29609 & 0.40520 \\
\hline Duration of diabetes mellitus & -0.05 & 0.03 & 0.057 & -0.11131 & 0.00167 \\
\hline Patient's weight & 0.01 & 0.01 & 0.048 & 0.00010 & 0.02143 \\
\hline $\begin{array}{l}\text { Duration of diabetes to other } \\
\text { family members }\end{array}$ & 0.03 & 0.14 & 0.818 & -0.24415 & 0.30911 \\
\hline $\begin{array}{l}\text { Dummy-private hospital } \\
\text { treatment }\end{array}$ & 0.50 & 0.18 & 0.006 & 0.14635 & 0.85385 \\
\hline Dummy-private clinic treatment & 0.18 & 0.21 & 0.395 & -0.23754 & 0.60244 \\
\hline
\end{tabular}

LR chi ${ }^{2}[11]=25.62 ;$ Prob $>$ chi $^{2}=0.0074 ;$ and Pseudo $\mathrm{R}^{2}=0.0500$

Table 2 also shows the impact of clinical attributes of the diabetic patients on the probability of change in self-care practices. The relationships of diabetes of other family members $(p=0.818)$ and dummy of patient's choice of private clinic for treatment compared with public sector hospitals $(p=0.395)$ with self-care practices were statistically insignificant, and the relationship of duration of diabetes with self-care practices ( $p$ $=0.057)$ was near to significant. In contrast, household income $(p=0.001)$, patient's weight $(p=0.048)$ and dummy of patient's choice of private hospitals for treatment compared with public sector hospitals $(p=0.006)$ with the probability of change in selfcare practices were statistically significant. Moreover, there was a negative relationship between duration of diabetes and probability of self-care practices (coefficient $=-0.05$ ), which showed that an increase of one year in the duration of diabetes resulted in a decline of $0.05 \%$ in the probability of self-care practices by the targeted patients. On the other hand, there was a positive relationship between patient's body weight and probability of self-care practices (coefficient $=0.01$ ) by the patients, which was witnessed as significant at $5 \%$.

Table 2 further shows that a rise of self-care practices by approximately $0.01 \%$ augments the probability of an increase in the patient's body weight by approximately $1 \mathrm{~kg}$. Regression analysis used the dummy of patients' choice of private clinic and private hospitals for treatment reference to public sector hospitals. Patients who visited 
private hospitals had a higher probability of self-care practices as compared with the patients seeking treatment from public sector hospitals. Furthermore, the regression model showed acceptable goodness of fit and was statistically significant as per given values of probability of chi square (Prob $>\mathrm{chi}^{2}=0.0074$ ).

TABLE 3: Marginal effects of predictors on different self-care practices of diabetic patients $[N=200]$

\begin{tabular}{|c|c|c|c|c|c|c|}
\hline \multirow{2}{*}{\multicolumn{2}{|c|}{$\begin{array}{l}\text { Indicators } \mathbf{d y / d x} \\
\text { Poor self-care practices of diabetic patients }\end{array}$}} & & \multirow[t]{2}{*}{$\mathbf{z}$} & \multirow[t]{2}{*}{ P-value } & \multicolumn{2}{|c|}{ 95\% Confidence Interval } \\
\hline & & & & & & \\
\hline Age & -0.0143 & 0.0281 & -0.51 & 0.611 & -0.06930 & 0.04072 \\
\hline Gender & -0.0767 & 0.0848 & -0.90 & 0.366 & -0.24286 & 0.08948 \\
\hline Dummy-marital status & 0.0616 & 0.0710 & 0.87 & 0.386 & -0.07761 & 0.20076 \\
\hline Household income & -0.0589 & 0.0182 & -3.24 & 0.001 & -0.09462 & -0.02323 \\
\hline Rural background of patient & -0.0426 & 0.0387 & -1.10 & 0.271 & -0.11856 & 0.03330 \\
\hline Family system & -0.0131 & 0.0434 & -0.30 & 0.764 & -0.09819 & 0.07206 \\
\hline Duration of diabetes mellitus & 0.0130 & 0.0069 & 1.88 & 0.060 & -0.00054 & 0.02645 \\
\hline Patient's weight & 0.0025 & 0.0013 & -1.95 & 0.051 & 71.60800 & 0.00001 \\
\hline $\begin{array}{l}\text { Duration of diabetes to other family } \\
\text { members }\end{array}$ & 76774 & 0.0334 & 0.23 & 0.818 & -0.07310 & 0.05775 \\
\hline Dummy-private hospital treatment & -0.1133 & 0.0403 & -2.81 & 0.005 & -0.19228 & -0.03442 \\
\hline Dummy-private clinic treatment & -0.0410 & 0.0457 & -0.90 & 0.370 & -0.13053 & 0.04858 \\
\hline \multicolumn{7}{|c|}{ Fair self-care practices of diabetic patients } \\
\hline Age & -0.0097 & 0.0192 & -0.51 & 0.612 & -0.04747 & 0.02797 \\
\hline Gender & -0.0464 & 0.0456 & -1.02 & 0.309 & -0.13576 & 0.04298 \\
\hline Dummy-marital status & 0.0457 & 0.0571 & 0.80 & 0.424 & -0.06626 & 0.15758 \\
\hline Household income & -0.0402 & 0.0141 & -2.85 & 0.004 & -0.06785 & -0.01257 \\
\hline Rural background of patient & -0.0284 & 0.0256 & -1.11 & 0.268 & -0.07852 & 0.02181 \\
\hline Family system & -0.0086 & 0.0279 & -0.31 & 0.756 & -0.06328 & 0.04599 \\
\hline Duration of diabetes mellitus & 0.0088 & 0.0049 & 1.79 & 0.074 & -0.00085 & 0.01853 \\
\hline Patient's weight & -0.0017 & 0.0009 & -1.86 & 0.063 & -0.00357 & 0.00009 \\
\hline $\begin{array}{l}\text { Duration of diabetes to other family } \\
\text { members }\end{array}$ & -0.0052 & 0.0228 & -0.23 & 0.818 & -0.04987 & 0.03940 \\
\hline Dummy-private hospital treatment & -0.0827 & 0.0333 & -2.49 & 0.013 & -0.14788 & -0.01747 \\
\hline Dummy-private clinic treatment & -0.0311 & 0.0387 & -0.80 & 0.422 & -0.10700 & 0.04478 \\
\hline \multicolumn{7}{|c|}{ Average self-care practices of diabetic patients } \\
\hline Age & 0.0126 & 0.0249 & 0.51 & 0.612 & -0.03611 & 0.06136 \\
\hline Gender & 0.0677 & 0.0745 & 0.91 & 0.364 & -0.07838 & 0.21377 \\
\hline Dummy-marital status & -0.0534 & 0.0602 & -0.89 & 0.375 & -0.17126 & 0.06455 \\
\hline Household income & 0.0521 & 0.0176 & 2.95 & 0.003 & 0.01751 & 0.08663 \\
\hline Rural background of patient & 0.0376 & 0.0345 & 1.09 & 0.276 & -0.03003 & 0.10530 \\
\hline Family system & 0.0116 & 0.0386 & 0.30 & 0.764 & -0.06406 & 0.08721 \\
\hline Duration of diabetes mellitus & -0.0115 & 0.0063 & -1.82 & 0.069 & -0.02380 & 0.00090 \\
\hline
\end{tabular}




\begin{tabular}{|c|c|c|c|c|c|c|}
\hline Indicators & $\mathrm{dy} / \mathrm{dx}$ & S. Error & $\mathbf{z}$ & P-value & \multicolumn{2}{|c|}{ 95\% Confidence Interval } \\
\hline Patient's weight & 0.0022 & 0.0012 & 1.89 & 0.059 & -0.00009 & 0.00459 \\
\hline $\begin{array}{l}\text { Duration of diabetes to other family } \\
\text { members }\end{array}$ & 0.0068 & 0.0295 & 0.23 & 0.818 & -0.05103 & 0.06460 \\
\hline Dummy-private hospital treatment & 0.0964 & 0.0352 & 2.74 & 0.006 & 0.02733 & 0.16545 \\
\hline Dummy-private clinic treatment & 0.0126 & 0.0249 & 0.51 & 0.612 & -0.03611 & 0.06136 \\
\hline \multicolumn{7}{|c|}{ Good self-care practices of diabetic patients } \\
\hline Age & 0.0114 & 0.0225 & 0.51 & 0.611 & -0.03259 & 0.05541 \\
\hline Gender & 0.0554 & 0.0558 & 0.99 & 0.321 & -0.05395 & 0.16473 \\
\hline Dummy-marital status & -0.0539 & 0.0681 & -0.79 & 0.429 & -0.18737 & 0.07962 \\
\hline Household income & 0.0471 & 0.0149 & 3.15 & 0.002 & 0.01781 & 0.07631 \\
\hline Rural background of patient & 0.0334 & 0.0298 & 1.12 & 0.264 & -0.02514 & 0.09185 \\
\hline Family system & 0.0101 & 0.0327 & 0.31 & 0.757 & -0.05399 & 0.07426 \\
\hline Duration of diabetes mellitus & -0.0103 & 0.0056 & -1.86 & 0.063 & -0.02125 & 0.00055 \\
\hline Patient's weight & 0.0020 & 0.0011 & 1.93 & 0.054 & -0.00003 & 0.00410 \\
\hline $\begin{array}{l}\text { Duration of diabetes mellitus to } \\
\text { other family members }\end{array}$ & 61317 & 0.0267 & 0.23 & 0.818 & -0.04612 & 0.05838 \\
\hline Dummy-private hospital treatment & 0.0996 & 0.0392 & 2.54 & 0.011 & 0.02283 & 0.17644 \\
\hline Dummy-private clinic treatment & 0.0365 & 0.0455 & 0.80 & 0.422 & 0.05267 & 0.12576 \\
\hline
\end{tabular}

Table 3 shows the marginal effects of different independent variables on the individual self-care levels of the target patients. It showed that household income $(p=0.001)$ and dummy of patient's choice of private hospitals for treatment compared with public sector hospitals $(p=0.005)$ were significantly influencing each category of the patients with poor self-care practices. Income had a negative contribution in poor $(\mathrm{dy} / \mathrm{dx}=-0.0589$, $Z=-3.24)$ and fair (dy/dx $=-0.0402, Z=-2.85$ ) self-care level of practices, whereas it had a positive role in average $(\mathrm{dy} / \mathrm{dx}=0.0521, Z=2.95)$ and good $(\mathrm{dy} / \mathrm{dx}=0.0471$, $Z=-0.79)$ self-care levels of practices. Table 3 further shows the marginal effects of different independent variables on the fair, average and good self-care practices of diabetic patients.

\section{Discussion}

The results of our study showed that household income was the only socio-economic indicator that was statistically significant and positively affected the probability of selfcare practices among diabetic patients. Additionally, patient's choice of hospital for treatment and clinical factors, including duration of diabetes, as well as patients' weight all showed a statistically significant relationship with self-care probability. Moreover, household income, duration of diabetes, body weight of the patients and patient's choice 
of private hospitals for treatment in comparison to public sector hospitals significantly influenced each category of self-care practices exercised by the patients. Income had a negative contribution in poor and fair self-care practices, whereas it positively affected average and good self-care practices.

The results of our study were consistent with previous studies that showed a positive and significant relationship between probability of self-care practices and household income [22-24]. The economic foundation of health and self-care practices (i.e. monthly household income) conforms to Maslow's hierarchy of needs that places meeting basic physiological needs ahead of the pursuit of higher-level health needs [23]. Therefore, patients with higher income might have better self-care health practices owing to better education, access to healthcare resources, economic capacity to develop their own way of life actively and nutritive diets [23, 25]. Conversely, the self-reported poor self-care practices of low-income patients might be due to low-education and a high dependency on the household breadwinner with their main consumption focused on clothing, food and other physiological needs, which leads them to pay less attention to their health $[22,23]$.

Although patients have reported low quality of services and longer wait times in public hospitals for appointments, treatment and follow-up, these disadvantages did not lead them to distrust public hospitals [26]. On the other hand, patients who provided positive feedback related to shorter wait times and higher quality of healthcare services in private hospitals generally indicated a distrust of public hospitals [26]. These results were consistent with a previous study conducted in Lahore, which showed that private hospitals were delivering better quality of services to their patients as compared to public hospitals [27]. However, contradictory results from a study conducted in Islamabad indicated that patients felt public hospitals were providing better services concerning lethal diseases, such as diabetes, when compared with private hospitals [28].

In the systematic review by Xiaoping et al., although many studies found that patients with longer duration of disease managed diabetes better [29], this was not supported by others $[29,30]$. It is an established fact that diabetes can be controlled by taking various cautionary measures but is not curable. The reason behind this negative relationship might be due to the persistency and chronicity of diabetes [31]. Owing to longer duration of diabetes, patients might become frustrated and relax their cautionary attitude towards self-care practices [31]. Moreover, a previous study also showed that patients with chronic type 2 diabetes who administered insulin as part of their good self-care practices were more likely to gain weight [32]. 
Generally, the intelligent quotient and decision power of two people is thought to be higher when compared with an individual [34]. Thus, married people may have better level of self-care practices as compared with those who are single. As far as self-care practices and gender nexus is concerned, the probability of good self-care practices is expected to be higher in males compared with females. As Pakistani society is male-centric with relatively high education and free mobility afforded to males only, they might have better opportunities to interact with various community members, understand, learn and practice good self-care [34]. It might be the reason for better selfcare levels of male patients than their women counterparts. A previous study showed significant relationship between socio-economic indicators including age, gender and marital status with different levels of self-care practices [29]. However, the results of our study showed contradictory results in line with the results of previous studies regarding age [22]. Another study showed that there was no significant relationship between quality of life of diabetic patients and their age, gender and marital status [24].

The strengths of this study include its use of well-validated measures of different levels of self-care practices to cope with diabetes. Another strength is using the interview method for data collection, which is a more appropriate method compared with selfcompletion of a questionnaire method due to the low literacy level of the participants. However, the limitations of this study include the cross-sectional nature of the study, which makes us cautious about causal relations. This study may be supplemented in the future with larger-scale surveys to strengthen the conclusions drawn about the socio-economic and clinical factors influencing self-care practices of diabetic patients.

\section{Conclusion}

In conclusion, socio-demographics and clinical indicators, including monthly household income, patient's choice of private hospitals for treatment in comparison to public sector hospitals and patient's weight, influence different levels of self-care practices among diabetic patients. Briefly, socio-demographic and clinical indicators played a decisive role in the health and self-management among type 2 diabetes patients. Income had a negative contribution in poor and fair self-care levels of practices, whereas it had a positive role in average and good self-care levels of practices. 


\section{Acknowledgements}

The authors sincerely thank Kathleen and Jennifer L. who supported in the proof-reading and content reviewing of the manuscript.

\section{References}

[1] International Diabetes Federation. (2017). Retrieved from: https://www.idf.org/ournetwork/regions-members/middle-east-and-north-africa/members/43-pakistan. html

[2] Ahmed, M. U., Seriwala, H. M., Danish, S. H., et al. (2016). Knowledge, attitude, and self-care practices amongst patients with type 2 diabetes in Pakistan. Global Journal of Health Science; vol. 8, no. 7, p. 1. doi: 10.5539/gjhs.v8n7p1.

[3] World Health Organization. (2016a). Global report on diabetes. Retrieved from http: //www.who.int/diabetes/global-report/en/

[4] World Health Organization. (2016s). The top 10 causes of death. Retrieved from: http://www.who.int/news-room/fact-sheets/detail/the-top-10-causes-of-death

[5] World Health Organization. (2016b). World Health Organization - Diabetes country profiles, 2016. Retrieved from: www.who.int/diabetes/country-profiles/pak_en.pdf

[6] Ansari, R. M., Dixon, J. B., and Browning, C. J. (2014). Self-management of type 2 diabetes in middle-aged population of Pakistan and Saudi Arabia. Open Journal of Preventive Medicine, vol. 4, no. 6, p. 396. doi: 10.4236/ojpm.2014.46047.

[7] Basit A, Riaz M, Fawwad A. Improving diabetes care in developing countries: The example of Pakistan. Diabetes Res Clin Pract 2015; 107 (2): 224-232. doi: 10.1016/j.diabres.2014.10.013.

[8] Hussain, A. and Ali, I. (2016). Diabetes mellitus in Pakistan: a major public health concern. Archives of Pharmacy Practice, vol. 7, no. 1, p. 30. doi: 0.4103/2045$080 \times .174943$.

[9] Tarin, S. M. (2010). Global 'Epidemic' of diabetes. Nishtar Medical Journal, vol. 2, pp. 56-60.

[10] Din, I. (2014). Health Outcomes and the Pakistani Population. Cambridge Scholars Publishing.

[11] Krag, M. Ø., Hasselbalch, L., Siersma, V., et al. (2016). The impact of gender on the long-term morbidity and mortality of patients with type 2 diabetes receiving structured personal care: a 13 year follow-up study. Diabetologia, vol. 59, no. 2, pp. 275-285. doi: 10.1007/s00125-015-3804-4. 
[12] Abubakari, A. R., Cousins, R., Thomas, C., et al. (2016). Sociodemographic and clinical predictors of self-management among people with poorly controlled type 1 and type 2 diabetes: the role of illness perceptions and self-efficacy. Journal of Diabetes Research, vol. 2016. doi: 10.1155/2016/6708164.

[13] Hill, J., Nielsen, M., and Fox, M. H. (2013). Understanding the social factors that contribute to diabetes: a means to informing health care and social policies for the chronically ill. Permanente Journal, vol. 17, no. 2, p. 67. doi: 10.7812/TPP/12-099.

[14] Mondesir, F. L., White, K., Liese, A. D., et al. (2015). Gender, illness-related diabetes social support, and glycemic control among middle-aged and older adults. Journals of Gerontology Series B: Psychological Sciences and Social Sciences, vol. 71, no. 6, pp. 1081-1088. doi: 10.1093/geronb/gbv061.

[15] Dagenais, G. R., Gerstein, H. C., Zhang, X., et al. (2016). Variations in diabetes prevalence in low-, middle-, and high-income countries: results from the prospective urban and rural epidemiological study. Diabetes Care, vol. 39, no. 5, pp. 780-787. doi: 10.2337/dc15-2338.

[16] Rahaman, K., Majdzadeh, R., Naieni, K., et al. (2017). Comorbidities and care practices of diabetic patients. Austin Journal of Public Health and Epidemiology, vol. 4, no. 2, p. 1059.

[17] Gonzalez-Zacarias, A. A., Mavarez-Martinez, A., Arias-Morales, C. E., et al. (2016). Impact of demographic, socioeconomic, and psychological factors on glycemic selfmanagement in adults with type 2 diabetes mellitus. Frontiers in Public Health, vol. 4, p. 195. doi: 10.3389/fpubh.2016.00195.

[18] Daoud, N., Osman, A., Hart, T. A., et al. (2015). Self-care management among patients with type 2 diabetes in East Jerusalem. Health Education Journal, vol. 74, no. 5, pp. 603-615. doi: 10.1177/0017896914555038.

[19] Economic Survey of Pakistan. (2018). Pakistan Economic Survey 2017-18. Retrieved from: http://www.finance.gov.pk/survey_1718.htm

[20] Agha, S. A., Usman, G., Agha, M. A., et al. (2014). Influence of socio-demographic factors on knowledge and practice of proper diabetic foot care. Khyber Medical University Journal, vol. 6, no. 1.

[21] Ather, N. A., Aziz, S., Javed, A., et al. (2016). Awareness of diabetic complications in type 2 diabetic patients. Journal of the Dow University of Health Sciences, vol. 10, no. 2, pp. 65-69.

[22] Bai, Y. L., Chiou, C. P., and Chang, Y. Y. (2009). Self-care behaviour and related factors in older people with Type 2 diabetes. Journal of Clinical Nursing, vol. 18, no. 23, pp. 3308-3315. doi: 10.1111/j.1365-2702.2009.02992.x. 
[23] Chen, C.-X., Feng, L.-N., and Li, S.-X. (2014). The correlation between socioeconomic status and health self-management in the elderly. International Journal of Nursing Sciences, vol. 1, no. 4, pp. 410-415. doi: 10.1016/j.ijnss.2014.10.008.

[24] Babazadeh, T., Dianatinasab, M., Daemi, A., et al. (2017). Association of self-care behaviors and quality of life among patients with type 2 diabetes mellitus: Chaldoran county, Iran. Diabetes \& Metabolism Journal, vol. 41, no. 6, pp. 449-456.

[25] Toobert, D. J., Hampson, S. E., and Glasgow, R. E. (2000). The summary of diabetes self-care activities measure: results from 7 studies and a revised scale. Diabetes Care, vol. 23, no. 7, pp. 943-950.

[26] Ward, P. R., Rokkas, P., Cenko, C., et al. (2017). 'Waiting for' and 'waiting in' public and private hospitals: a qualitative study of patient trust in South Australia. BMC Health Services Research, vol. 17, no. 1, p. 333. doi: 10.1186/s12913-017-2281-5.

[27] Irfan, S. and ljaz, A. (2011). Comparison of service quality between private and public hospitals: empirical evidences from Pakistan. Journal of Quality and Technology Management, vol. 7, no. 1, pp. 1-22. doi: 10.1177/0971890720130105.

[28] Shabbir, S., Kaufmann, H. R., and Shehzad, M. (2010). Service quality, word of mouth and trust: drivers to achieve patient satisfaction. Scientific Research and Essays, vol. 5, no. 17, pp. 2457-2462.

[29] Luo, X., Liu, T., Yuan, X., et al. (2015). Factors influencing self-management in Chinese adults with Type 2 diabetes: a systematic review and meta-analysis. International Journal of Environmental Research and Public Health, vol. 12, no. 9, pp. 11304-11327. doi: 10.3390/ijerph120911304.

[30] Yu, P. (2009). The Relationship between coping strategy, health beliefs and selfmanagement among people with type 2 diabetes in Changsha. The Master's Thesis, Central South University: Changsha, China,.

[31] Hailu, E., Mariam, W. H., Belachew, T., et al. (2012). Self-care practice and glycaemic control amongst adults with diabetes at the Jimma University Specialized Hospital in south-west Ethiopia: a cross-sectional study. African Journal of Primary Health Care \& Family Medicine, vol. 4, no. 1, pp. 1-6. doi: 10.4102/phcfm.v4i1.311.

[32] Cichosz, S. L., Lundby-Christensen, L., Johansen, M. D., et al. (2017). Prediction of excessive weight gain in insulin treated patients with type 2 diabetes. Journal of Diabetes, vol. 9, no. 4, pp. 325-331. doi: 10.1111/1753-0407.12418.

[33] Elwyn, G., Edwards, A., Gwyn, R., et al. (1999). Towards a feasible model for shared decision making: focus group study with general practice registrars. BMJ, vol. 319, no. 7212 , pp. 753-756. doi: 10.1136/bmj.319.7212.753. 
[34] Shrivastava, S. R., Shrivastava, P. S., and Ramasamy, J. (2013). Role of self-care in management of diabetes mellitus. Journal of Diabetes \& Metabolic Disorders, vol. 12, no. 1, p. 14. doi: 10.1186/2251-6581-12-14. 